\title{
Models for estimating projections for the prevalence and disease burden of chronic obstructive pulmonary disease (COPD): systematic review protocol
}

\author{
*Susannah McLean', Sarah H Wild², Colin R Simpson', Aziz Sheikh" \\ Allergy and Respiratory Research Group, Centre for Population Health Sciences, The University of Edinburgh, Edinburgh, UK \\ 2 Centre for Population Health Sciences, The University of Edinburgh, Edinburgh, UK
}

Received 20th March 2013; revised 16th April 2013; accepted 24th April 2013; online 30th May 2013

(C) 2013 Primary Care Respiratory Society UK. All rights reserved.

S McLean et al. Prim Care Respir J 2013; 22(2): PS8-PS21

http://dx.doi.org/10.4104/pcrj.2013.00048

Keywords COPD, epidemiology, modelling

\section{Introduction}

Policymakers and governments must decide their healthcare priorities on the basis of the best healthcare intelligence available to them. Recent interest has increasingly focused on the global implications of an increasing and elderly population with long-term conditions. $^{1-3}$ The most recent figures from the Global Burden of Disease Study 2010 show that the third top global cause of death was chronic obstructive pulmonary disease (COPD), ${ }^{4}$ rising from fourth place in $1990 .{ }^{5}$ It is predominantly caused by cigarette smoking and leads to lung airflow limitation, cough, excessive sputum production, and breathlessness. People with COPD can suffer from substantial disability as the condition progresses. ${ }^{6} \mathrm{~A}$ pressing challenge for governments is how best to project the future trend in the prevalence and burden of COPD in order to plan adequate health and social care for those affected by this condition within the scope of limited resources. Governments should ideally be planning for COPD on two levels: (1) they should consider how to manage resources to care and treat people who are already affected by COPD; and (2) how to prevent a greater increase in the burden from COPD by minimising the continuing smoking epidemic.

In order to make such calculations, governments and other healthcare providers need to draw on epidemiological models. Merriam-Webster's dictionary defines a 'model' as 'a system of postulates, data, and inferences presented as a mathematical description of an entity or state of affairs'. This is a useful starting point when considering the role of models in epidemiology. Most models are explanatory in nature and describe the relationships between different parameters. The focus of this study is on models which help to project future epidemiological trends and patterns in populations with COPD. Governments and policymakers have access to many models, but a review is required to appraise the published COPD models to aid selection between them.

Various features of COPD present a particular challenge to mathematical and epidemiological modelling, including the many different definitions of a COPD diagnosis and its overlap with a diagnosis of asthma. Although COPD is most clearly attributable to cigarette smoking, there is debate over how best to classify nonsmokers who develop COPD with the immunological and pathological features of COPD as a result of exposure to occupational dusts and gases or recurrent chest infections. In addition, there is uncertainty as to the correct classification of older non-smoking adults who have evidence of lung cell remodelling including squamous metaplasia following chronic inflammation due to long-term asthma. Such older adults have often lost the reversibility in their airways obstruction and demonstrate spirometry which is consistent with the thresholds for COPD. ${ }^{7-9}$

According to the Global Initiative for Chronic Obstructive Lung Disease (GOLD), the diagnosis of COPD is characterised by an obstructive lung defect with forced expiratory volume in one second to forced vital capacity $\left(\mathrm{FEV}_{1} / \mathrm{FVC}\right)$ ratio $<0.7 .{ }^{10}$ Controversy regarding this threshold also complicates decisions of precisely which population to include in modelling. Lung function decreases with age, so a proportion of elderly people (age 75+) who have never smoked still fit these criteria for COPD. Some doctors reasonably argue that such elderly people really have normal lung function for their age and that medicalisation of the elderly should be avoided. ${ }^{7}$ An alternative threshold of the lower limit of normal for $\mathrm{FEV}_{1} / \mathrm{FVC}$ has been proposed with a decreasing threshold according

\footnotetext{
* Corresponding author: Dr Susannah McLean, Allergy and Respiratory Research Group, Centre for Population Health Sciences, The University of Edinburgh, Edinburgh EH8 9DX, UK. Tel: +44 (0)1316509242 E-mail: Susannah.mclean@ed.ac.uk
} 
to age by percentile. The bottom $5 \%$ of $\mathrm{FEV}_{1} / \mathrm{FVC}$ measurements for whichever total population being measured would be considered abnormal in the older age group. ${ }^{9}$ However, no up-to-date large standardised population database currently exists to validate such a measure. The nearest is the use of the European Coal and Steel Workers Population to provide percent predicted $\mathrm{FEV}_{1}$ values; however, this population was standardised over 20 years ago and is based on a working white European population without ethnic

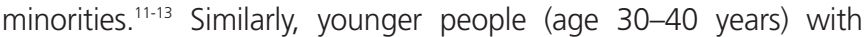
larger FVC values and greater respiratory reserve may already have sustained COPD-type damage to their lungs before they reach the $<0.7$ ratio threshold, so at this end of the age range there is a risk of under-diagnosis of COPD. ${ }^{13}$

The debate regarding the diagnosis of COPD is more than just a debate over spirometry thresholds. As many developing countries do not have access to spirometry or even to a reliable power supply, the usefulness of such diagnostic thresholds is limited. It has been proposed that COPD may also be diagnosed on history and clinical features. However, studies have shown that using clinical indicators of pulmonary function to diagnose COPD missed many participants who had low lung function and airways obstruction, especially in current smokers. ${ }^{14}$ Therefore, in many countries the current situation has evolved where COPD is diagnosed from physician opinion without corroborating evidence from spirometry, resulting in a significant overlap between a diagnosis of COPD and a diagnosis of asthma.

It seems likely that classifications in the future will evolve as the role of host susceptibility is increasingly understood in terms of genetic and epigenetic features. Several candidate genes related to COPD have been identified. ${ }^{15}$ In addition, the science of epigenetics helps to explain how DNA transcription has been activated or suppressed by DNA methylation, acetylation, or other mechanisms in response to predominantly prenatal and early life environmental influences. ${ }^{16}$ The result of such switching on or off of DNA transcription is to determine the host's response to noxious stimuli including cigarette smoke. Increased understanding of these factors is helping to unravel the mysteries of why some life-long smokers are virtually unaffected by their habit while others have severe COPD. Estimates as to the prevalence of COPD among smokers aged $>45$ years vary from $15 \%$ to $50 \%$ according to the criteria used for diagnosis. ${ }^{17,18}$

Modelling COPD is also challenged by the key feature of exacerbations. An exacerbation may be triggered by increased bacterial or viral load in the lungs which induce an aggressive immune response and associated clinical features. ${ }^{19-21}$ Associated with a greater frequency of exacerbations is higher morbidity, due to faster disease progression in terms of loss of lung function, and also mortality. ${ }^{21}$

An additional challenge is the level of mathematical sophistication within each model. Ideally, a researcher with considerable statistical skill would be available to check the algorithms that drive each model and so provide a full appraisal of the quality of each model. In the absence of this ideal, it was decided to appraise the quality of reporting of each model as a proxy for the model's mathematical quality. Taking these challenges into account, it will be necessary to describe a degree of context with each model in order that it can be applied in an appropriate setting. This will help subsequent researchers to understand the necessary caveats to include when describing the results from each model.

\section{Objectives}

To identify all available models for estimating projections of COPD prevalence and burden, and to assess the quality of reporting of each model in its key publication.

\section{Methods}

A search strategy has been developed using search terms to cover the three concepts of 'modelling', 'disease burden', and 'chronic obstructive pulmonary disease' (see Appendix 1 for full details). Searches will be conducted in the following electronic databases: MEDLINE, EMBASE, CAB Abstracts, World Health Organization (WHO) Library and Information Services (WHOLIS - library catalogue of books and reports), WHO Regional Indexes (AIM (AFRO), LILACS (AMRO/PAHO), IMEMR (EMRO), IMSEAR (SEARO), WPRIM (WPRO)), and a modified search strategy will be used to identify reports from the WHO home website and Google. Searches will be for both published and unpublished modelling studies from 1980 (when modelling methods first began to be widely used) to 2013. Two authors will independently review the studies against the inclusion criteria and make a decision as to whether the study is suitable. Disagreements will be resolved by discussion and, if this is not possible, a third reviewer will arbitrate.

\section{Inclusion criteria}

Any modelling study which uses demographic and epidemiological data to project the prevalence and disease burden will be included. The included projected outcomes which are of interest are one or more of: incidence, prevalence and mortality, and disease burden. With regard to 'disease burden', the outcomes of interest can be considered from the individual's point of view, from the point of view of the healthcare system, and from the point of view of broader society. For the purposes of this review, the focus is on the perspective of the healthcare system. Other perspectives are valid; however, different instruments are used to measure them and the purpose of this study is to guide policymakers who will focus on the healthcare system perspective. Quality-adjusted life years (QALYs) and disability-adjusted life years (DALYs) are often used to measure and quantify the burden to the individual of the morbidity they are suffering. Treatments are assigned a cost per restored QALY, and this is an important measure used in cost-effectiveness studies. However, the scope of this study is more limited in order to avoid confusion of perspectives. Some of the studies included may discuss QALYs and DALYs, but they have not been chosen as primary disease burden outcomes for this review. Instead, we will concentrate on primary care visits, emergency department visits, hospital admissions, and COPD treatment costs.

\section{Exclusion criteria}

There will be no exclusions on the basis of language of the report. Studies which are population-based surveys of prevalence without 
modelling will be excluded as there has recently been a systematic review of such studies.22 'Models' will be excluded if they describe animals, cell lines, clinical series, or estimates of individual risk (such as individual prognostic models). Decision analytical models or decision support models will be excluded where they refer to clinical decision-making for individuals rather than populations. Models that compare one intervention with another intervention will also be excluded, as the aim is accurately to project the baseline outcomes so it is premature to take into account the effect of interventions. Also excluded will be regression models which start with a COPD population and 'back-calculate' the prevalence or burden using regression to quantify risk factors, as this follows a different logic from that of projection modelling.

\section{Participants}

The source population for the model may be from anywhere in the world. The model will pertain to adult populations aged $>40$ years as it is usually not appropriate to diagnose COPD in younger people. ${ }^{10}$ COPD may be diagnosed by physician, spirometry, or by questionnaire. Other assumptions regarding the diagnosis of COPD will be evaluated in the context of the model.

\section{Data extraction}

The data will be extracted by one author and checked by a second. Data will be extracted using a pre-piloted data extraction form. The following identification details will be extracted for each model: author and email address, year, institution, and funding source. These data will be followed by: the purpose of the model, model title, model type, model setting, time period, and population (age, sex and country). Also extracted will be: inputs to the model, source of input data, details of processing of the model, outcomes for COPD (incidence, prevalence, mortality, GP visits, emergency department visits, hospitalisations, treatment costs), model output/results, details of the model's availability, any comparisons with other studies, social and economic policy implications of model outcomes, and future research recommendations. In this way, the data extraction form aims to encompass a comprehensive picture of the model.

\section{Quality appraisal framework}

Ideally, a quality appraisal of the actual modelling process would be undertaken. However, this requires significant statistical technical expertise. A pragmatic decision has therefore been made to quality appraise the reporting of the models rather than the actual modelling process for those that have full published reports. In order to do this, a quality of reporting framework has been designed following review of key guidelines as to good practice in modelling. ${ }^{23-26} \mathrm{~A}$ scoring mechanism was devised in collaboration with Simon Capewell of Liverpool University ${ }^{27}$ to weight the importance of the different elements required to produce a relevant high-quality model (see Appendix 2).

\section{Strategy for data synthesis}

The study will be the unit of analysis. Models will be described and classified. A detailed critical narrative synthesis of the highest scoring models will be undertaken. Where the models are not available, we will write to the model authors for further clarification. No subgroup analysis is planned.

\section{Handling editor David Bellamy}

Conflicts of interest The authors declare that they have no conflicts of interest in relation to this protocol. AS is Joint Editor-in-Chief of the PCRJ, but was not involved in the editorial review of, nor the decision to publish, this protocol.

Contributorship SM drafted the article with oversight from CS SW and AS. AS and SM conceived the project as part of SM's PhD.

Funding SM is funded by the University of Edinburgh's Principal's Career Development PhD Scholarship.

Protocol registration $A$ shortened version of this protocol has been registered online in the PROSPERO University of York database: Systematic review of models for estimation and future projecting of the prevalence and the disease burden of chronic obstructive pulmonary disease (COPD), PROSPERO 2012:CRD42012002623, available from http://www.crd.york.ac.uk/PROSPERO/ display_record.asp?ID=CRD42012002623

\section{References}

1. Lim S, Vos T, Flaxman A, et al. A comparative risk assessment of burden of disease and injury attributable to 67 risk factors and risk factor clusters in 21 regions, 1990-2010: a systematic analysis for the Global Burden of Disease Study 2010. Lancet 2012;380(9859):2224-60.

http://dx.doi.org/10.1016/S0140-6736(12) 61766-8

2. Murray CJ, Vos T, Lozano R, et al. Disability-adjusted life years (DALYs) for 291 diseases and injuries in 21 regions, 1990-2010: a systematic analysis for the Global Burden of Disease Study 2010. Lancet 2012;380(9859):2197-223. http://dx.doi.org/10.1016/S0140-6736(12)61689-4

3. Department of Health. Improving the health and wellbeing of people with long term conditions: London: Department of Health, 2010.

4. Lozzano R, Naghavi M, Foreman K, et al. Global and regional mortality from 235 causes of death for 20 age groups in 1990 and 2010: a systematic analysis for the Global Burden of Disease Study 2010. Lancet 2012;380(9859):2095-128. http://dx.doi.org/10.1016/S0140-6736(12)61728-0

5. Mathers CD, Loncar D. Projections of global mortality and burden of disease from 2002 to 2030. PLoS Med 2006;3(11):e442

http://dx.doi.org/10.1371/journal.pmed.0030442

6. Pauwels R, Rabe K. Burden and clinical features of chronic obstructive pulmonary disease (COPD). Lancet 2004;364(9434):613-20. http://dx.doi.org/10.1016/S0140-6736(04)16855-4

7. Mannino DM, Buist SA, Vollmer WM. Chronic obstructive pulmonary disease in the older adult: what defines abnormal lung function? Thorax 2007;62(3):237-41. http://dx.doi.org/10.1136/thx.2006.068379

8. Price D, Freeman D, Cleland J, Kaplan A, Cerasoli F. Earlier diagnosis and earlier treatment of COPD in primary care. Prim Care Respir J 2010;20(1):15-22. http://dx.doi.org/10.4104/pcrj.2010.00060

9. Mohamed Hoesein FAA, Zanen P, Lammers J-WJ. Lower limit of normal or FEV1/FVC <0.70 in diagnosing COPD: an evidence-based review. Respir Med 2011;105(6):907-15. http://dx.doi.org/10.1016/j.rmed.2011.01.008

10. GOLD. Global Initiative for Chronic Obstructive Lung Disease: Pocket guide to COPD diagnosis, management and prevention. 2010. http://www.goldcopd.org/guidelines-pocket-guide-to-copd-diagnosis.html

11. Miller MR, Quanjer PH, Swanney MP, Ruppel G, Enright PL. Interpreting lung function data using $80 \%$ predicted and fixed thresholds misclassifies more than 20\% of patients. Chest 2011;139(1):52-9. http://dx.doi.org/10.1378/chest.100189

12. Quanjer PH, Enright PL, Miller MR, et al. The need to change the method for defining mild airway obstruction. Eur Respir J 2011;37(3):720-2. http://dx.doi.org/10.1183/09031936.00135110

13. Swanney MP, Ruppel G, Enright PL, et al. Using the lower limit of normal for the FEV1/FVC ratio reduces the misclassification of airway obstruction. Thorax 2008;63(12):1046-51. http://dx.doi.org/10.1136/thx.2008.098483

14. Mannino D, Etzel RA, Flanders WD. Do the medical history and physical examination predict low lung function? Arch Intern Med 1993;153(16):1892-7. http://dx.doi.org/10.1001/archinte.1993.00410160052004

15. Bakke PS, Zhu G, Gulsvik A, et al. Candidate genes for COPD in two large data sets. Eur Respir J 2011;37(2):255-63. 
http://dx.doi.org/10.1183/09031936.00091709

16. Sakao S, Tatsumi K. The importance of epigenetics in the development of chronic obstructive pulmonary disease. Respirology 2011;16(7):1056-63. http://dx.doi.org/10.111/j.440-843.2011.02032.x.

17. Lundback $B$, Lindberg $A$, Lindstrom $M$, et al. Not 15 but $50 \%$ of smokers develop COPD? Report from the Obstructive Lung Disease in Northern Sweden Studies Respir Med 2003;97(2):115-22. http://dx.doi.org/10.1053/rmed.2003.1446

18. Barker DJP, Godfrey KM, Fall C, Osmond C, Winter PD, Shaheen SO. Relation of birth weight and childhood respiratory infection to adult lung function and death from chronic obstructive airways disease. BMJ 1991;21(303):671-5. http://dx.doi.org/10.1136/bmj.303.6804.671

19. Brusselle G, Joos G, Bracke KR. New insights into the immunology of chronic obstructive pulmonary disease. Lancet 2011;378(9795):1015-26. http://dx.doi.org/10.16/S0140-6736(11)60988-4.

20. Garcha D, Thurston S, Patel A, et al. Changes in prevalence and load of airway bacteria using quantitative PCR in stable and exacerbated COPD. Thorax 2012;67(12):1075-80. http://dx.doi.org/10.136/thoraxjnl-2012-201924.

21. Wedizcha JA, Donaldson GC. Natural history of successive COPD exacerbations. Thorax 2012;67(11):935-6. http://dx.doi.org/10.1136/thoraxjnl-2012-202087

22. Atsou K, Chouaid C, Hejblum G. Variability of the chronic obstructive pulmonary disease key epidemiological data in Europe: systematic review. BMC Med 2011;9:7. http://dx.doi.org/10.1186/1741-7015-9-7

23. Weinstein MC, Toy EL, Sandberg EA, et al. Modeling for health care and other policy decisions: uses, roles, and validity. Value Health 2001;4(5):348-61. http://dx.doi.org/10.1046/j.1524-4733.2001.45061.x

24. Weinstein MC, O'Brien B, Hornberger J, et al. Principles of good practice for decision analytic modeling in health-care evaluation: report of the ISPOR Task Force on Good Research Practices-Modeling Studies. Value Health 2003;6(1):9-17. http://dx.doi.org/10.1046/j.1524-4733.2003.00234.x

25. Philips Z, Bojke L, Sculpher M, Claxton K, Golder S. Good practice guidelines for decision-analytic modelling in health technology assessment: a review and consolidation of quality assessment. Pharmacoeconomics 2006;24(4):355-71. http://dx.doi.org/10.2165/00019053-200624040-00006

26. Weinstein MC. Methodologic issues in policy modeling for cardiovascular disease. J Am Coll Cardiol 1989;14(3 Suppl A):38-43A. http://dx.doi.org/10.1016/0735-1097(89)90160-5

27. Unal B, Capewell S, Critchley JA. Coronary heart disease policy models: a systematic review. BMC Public Health 2006;6:213. http://dx.doi.org/10.1186/1471-2458-6-213

\section{Available online at http://www.thepcrj.org}




\section{Appendix 1: Search Strategy}

Medline copd and burden model - 1946 to week 4 March 2012

animals/

2 humans/

$3 \quad 1$ not (1 and 2)

$4 \quad 2$ not 3

5 lung diseases, obstructive/

6 exp pulmonary disease,chronic obstructive/

$7 \quad$ emphysem*.mp.

$8 \quad$ (chronic* adj3 bronchiti*).mp.

9 (obstruct* adj3 (pulmonary or lung* or airway* or airflow* or bronch* or respirat*)).mp.

10 COPD.mp.

11 COAD.mp.

12 COBD.mp

13 AECB.mp.

(exacerbation* adj3 bronchiti*).mp. [mp=title, abstract, original title, name of substance

14 word, subject heading word, protocol supplementary concept, rare disease supplementary concept, unique identifier]

155 or 6 or 7 or 8 or 9 or 10 or 11 or 12 or 13 or 14

$16 \quad 4$ and 15

17 prevalence/

$18 \quad$ Incidence/

19 "cost of illness"/ or forecasting/ or "quality of life"/

20 "burden of illness".mp.

21 quality-adjusted life years/ or models, statistical/ or monte carlo method/

22 Health Care Rationing/ or "disability adjusted life years".mp.

$23 \quad$ "Cause of Death"/

24 Hospitalization/

25 house calls/ or office visits/ or "referral and consultation"/ 


\section{Appendix 1: Search Strategy}

27 (model.mp. or modelling.mp.)

2826 and 27

\section{Embase copd and burden model}

1. $\exp$ ANIMAL/

2. Nonhuman/

3. Human/

4. 1 or 2

5. 3 not 4

6. Chronic obstructive lung disease/

7. Obstructive airway disease/

8. chronic bronchitis/

9. lung emphysema/

10. (Chronic\$ adj3 bronchiti\$).mp.

11. (obstruct\$ adj3 (pulmonary or lung\$ or airway\$ or airflow\$ or bronch\$ or respirat\$)).mp.

12. COPD.mp.

13. COAD.mp.

14. COBD.mp.

15. AECB.mp.

16. (Acute exacerbation adj3 chronic bronchitis).mp. [ $\mathrm{mp}=$ title, abstract, subject headings, heading word, drug trade name, original title, device manufacturer, drug manufacturer, device trade name, keyword]

17.6 or 7 or 8 or 9 or 10 or 11 or 12 or 13 or 14 or 15 or 16

18. 5 and 17

19. prevalence/

20. incidence/

21. "cost of illness"/ or "health care cost"/

22. mortality/

23. "burden of disease".mp.

24. quality adjusted life year/ or "quality of life"/

25. "disability adjusted life year".mp.

26. morbidity/

27. 19 or 20 or 21 or 22 or 23 or 24 or 25 or 26

28. 18 and 27

29 (model.mp. or modelling.mp.)

3028 and 29

CAB abstracts

COPD and burden model 
Appendix 1: Search Strategy

1. Animal.mp. [mp=abstract, title, original title, broad terms, heading words]

2. animal.mp.

3. human diseases.sh.

4. 3 not 2

5. chronic obstructive pulmonary disease.sh.

6. (chronic adj3 bronchit\$).mp. [mp=abstract, title, original title, broad terms, heading words]

7. pulmonary emphysema/

8. chronic obstructive lung disease.mp.

9. (obstruct $\$$ adj3 (pulmonary or lung\$ or airway\$ or airflow\$ or bronch $\$$ or respirat\$)).mp.

10. COPD.mp.

11. COAD.mp.

12. COBD.mp.

13. AECB.mp.

14. (exacerbat $\$$ adj3 bronchi\$).mp. [mp=abstract, title, original title, broad terms, heading words]

15. bronchitis.sh.

16. 5 or 6 or 7 or 8 or 9 or 10 or 11 or 12 or 13 or 14 or 15

17. 3 and 16

18. prevalent.mp. or disease prevalence.sh.

19. incidence.sh.

20. "burden of disease".mp.

21. economic impact.sh.

22. "causes of death"/

23. morbidity/

24. health services/

25. "house call".mp.

26. health care costs/

27. "cost benefit analysis"/

28. 18 or 19 or 20 or 21 or 22 or 23 or 24 or 25 or 26 or 27

29. 17 and 28

30 (model.mp. or modelling.mp.)

3129 and 30 
WHOLIS (World Health Organization Library Information Services)

"chronic obstructive pulmonary disease" and prevalence - 0 results

("chronic obstructive pulmonary disease" or bronchitis or emphysema) and prevalence - 0

("chronic obstructive pulmonary disease" or bronchitis or emphysema) and (prevalence or incidence or mortality or morbidity)

\section{Global Health Library Regional Indexes}

("chronic obstructive pulmonary disease" or bronchitis or emphysema) and (prevalence or incidence or mortality or morbidity)

AIM (AFRO),

LILACS (AMRO/PAHO),

IMEMR (EMRO),

IMSEAR (SEARO),

WPRIM (WPRO) 
Appendix 2: Data extraction and quality of reporting

\begin{tabular}{|l|l|}
\hline Reference & \\
\hline Author and email address & \\
\hline Year & \\
\hline Institution & \\
\hline Funding source & \\
\hline Purpose of model & \\
\hline Model Title & \\
\hline Model Type & \\
\hline $\begin{array}{l}\text { Model setting, time period and } \\
\text { population (age, sex and } \\
\text { country). }\end{array}$ & \\
\hline $\begin{array}{l}\text { Inputs to model } \\
\text { Details of model's processing } \\
\text { (including algorithm) }\end{array}$ & \\
\hline \multicolumn{2}{|l|}{} \\
\hline Model output/ results & \\
\hline $\begin{array}{l}\text { Model availability } \\
\text { recommendations }\end{array}$ & \\
\hline $\begin{array}{l}\text { Social and economic policy } \\
\text { implications of model outcomes }\end{array}$ & \\
\hline Any other comments & \\
\hline
\end{tabular}

Risk Factors Included - not a risk factor study

\begin{tabular}{|l|l|l|l|}
\hline Risk Factor & Tick if included & Form (Con/Cat) & $\begin{array}{l}\text { Describe } \\
\text { intervention }\end{array}$ \\
\hline Smoking & & & \\
\hline Indoor air pollution & & & \\
\hline Outdoor air pollution & & & \\
\hline Socioeconomic deprivation & & & \\
\hline Nutrition & & & \\
\hline Other & & & \\
\hline Pulmonary rehabilitation & & & \\
\hline Smoking cessation & & & \\
\hline Bronchodilator & & & \\
\hline Corticosteroid & & & \\
\hline Other treatment & & & \\
\hline & & & \\
\hline
\end{tabular}


Appendix 2: Data extraction and quality of reporting

Disease categories included - please tick

\begin{tabular}{|c|c|c|c|c|c|c|}
\hline & & $\begin{array}{ll}\text { NICE } & 12 \\
2004 & \end{array}$ & $\begin{array}{l}\text { ATS/ERS } \\
2004\end{array}$ & GOLD $2010^{6}$ & $\begin{array}{l}\text { NICE } 101 \\
\text { update } \\
2011^{30}\end{array}$ & $\begin{array}{l}\text { Please } \\
\text { Tick } \\
\text { Category }\end{array}$ \\
\hline $\begin{array}{l}\text { Post- } \\
\text { bronchodilator } \\
\text { FEV1/FVC }\end{array}$ & $\begin{array}{l}\text { FEV1 } \% \\
\text { predicted }\end{array}$ & \multicolumn{4}{|c|}{ Severity of airflow obstruction } & \\
\hline \multirow[t]{4}{*}{$<0.7$} & $\geq 80 \%$ & & Mild & $\begin{array}{lll}\text { Stage } 1 & - \\
\text { Mild } & & \\
\end{array}$ & $\begin{array}{lll}\text { Stage } & 1 & - \\
\text { Mild* } & & \\
\end{array}$ & \\
\hline & $50-79 \%$ & Mild & Moderate & $\begin{array}{l}\text { Stage } 2- \\
\text { Moderate }\end{array}$ & $\begin{array}{ll}\text { Stage } 2 ~- \\
\text { Moderate }\end{array}$ & \\
\hline & $30-49 \%$ & Moderate & Severe & $\begin{array}{l}\text { Stage } 3- \\
\text { Severe }\end{array}$ & $\begin{array}{l}\text { Stage } \\
\text { Severe }\end{array}$ & \\
\hline & $<30 \%$ & Severe & Very Severe & $\begin{array}{l}\text { Stage 4- } \\
\text { Very } \\
\text { Severe** }\end{array}$ & $\begin{array}{l}\text { Stage } \\
\text { Very } \\
\text { Severe** }\end{array}$ & \\
\hline
\end{tabular}

* symptoms should be present to diagnose COPD in people with NICE 2011 mild airflow obstruction.

$* *$ or FEV $1<50 \%$ with respiratory failure 
Appendix 2: Data extraction and quality of reporting

Outcomes studied

\begin{tabular}{|c|c|c|}
\hline $\begin{array}{l}\text { What is the prevalence of COPD per } \\
\text { region? }\end{array}$ & Prevalence rate & \\
\hline $\begin{array}{l}\text { What is the incidence of COPD per } \\
\text { region? }\end{array}$ & $\begin{array}{l}\text { New cases per thousand } \\
\text { person years }\end{array}$ & \\
\hline $\begin{array}{l}\text { What is the COPD disease-specific } \\
\text { mortality? }\end{array}$ & COPD-related mortality & \\
\hline $\begin{array}{l}\text { What is the COPD disease-specific } \\
\text { burden to the individual? }\end{array}$ & $\begin{array}{l}\text { Disability/quality adjusted } \\
\text { life years lived with } \\
\text { mild/moderate/severe COPD } \\
\text { Monetary cost of COPD } \\
\text { healthcare to the individual }\end{array}$ & \\
\hline $\begin{array}{l}\text { What is the COPD disease-specific } \\
\text { burden to the healthcare system? }\end{array}$ & $\begin{array}{l}\text { Average annual GP visits } \\
\text { Average annual emergency } \\
\text { dept visits } \\
\text { Average annual hospital } \\
\text { admissions per patient for } \\
\text { COPD exacerbations } \\
\text { Average annual } \\
\text { readmissions per patient } \\
\text { (measure of effectiveness of } \\
\text { treatment) }\end{array}$ & \\
\hline $\begin{array}{l}\text { What is the COPD-specific burden to } \\
\text { society }\end{array}$ & $\begin{array}{l}\text { Cost of healthcare } \\
\text { cumulative loss of earnings } \\
\text { by patients } \\
\text { cumulative loss of time at } \\
\text { work/study } \\
\text { carers burden }\end{array}$ & \\
\hline \multicolumn{3}{|l|}{ Other } \\
\hline $\begin{array}{l}\text { What is the "main outcome" of } \\
\text { the study in the author's words }\end{array}$ & & \\
\hline
\end{tabular}


Appendix 2: Data extraction and quality of reporting

\section{QUALITY OF REPORTING ASSESSMENT}

Model purpose and aim

\begin{tabular}{|l|l|}
\hline $\begin{array}{l}\text { Statement of the question which the model is } \\
\text { trying to answer }\end{array}$ & \\
\hline Perspective of model & \\
\hline Time horizon of model & \\
\hline Model type & \\
\hline
\end{tabular}

Transparency

\begin{tabular}{|l|l|l|}
\hline Transparency & Not available & Available \\
\hline Illustrations/examples & & \\
\hline Assumptions & & \\
\hline Model availability for reader & & \\
\hline
\end{tabular}

Data Input: - not much detail given

\begin{tabular}{|c|c|c|c|}
\hline Type of data & Source & $\begin{array}{l}\text { Comment on } \\
\text { quality (sample } \\
\text { size and response } \\
\text { rate for surveys } \\
\text { etc.) }\end{array}$ & Limitations \\
\hline \multicolumn{4}{|l|}{$\begin{array}{l}\text { Population } \\
\text { data }\end{array}$} \\
\hline \multicolumn{4}{|l|}{$\begin{array}{l}\text { Mortality } \\
\text { data/rate }\end{array}$} \\
\hline \multicolumn{4}{|l|}{$\begin{array}{l}\text { Morbidity } \\
\text { data/rate }\end{array}$} \\
\hline \multicolumn{4}{|l|}{$\begin{array}{l}\text { Treatment } \\
\text { uptake }\end{array}$} \\
\hline \multicolumn{4}{|l|}{$\begin{array}{l}\text { Risk factor } \\
\text { prevalence/t } \\
\text { rends }\end{array}$} \\
\hline \multicolumn{4}{|l|}{$\begin{array}{l}\text { Treatment } \\
\text { effectiveness }\end{array}$} \\
\hline \multicolumn{4}{|l|}{$\begin{array}{l}\text { Risk factor } \\
\text { change } \\
\text { effectiveness } \\
\text { /Betas } \\
\end{array}$} \\
\hline \multicolumn{4}{|l|}{ Costs } \\
\hline $\begin{array}{l}\text { Health } \\
\text { utilities }\end{array}$ & & & \\
\hline
\end{tabular}

Data modelling

\begin{tabular}{|l|l|}
\hline Discussion of model's derivation & \\
\hline Assumptions documented and justified & \\
\hline $\begin{array}{l}\text { Model consistent with accepted techniques of } \\
\text { statistics and epidemiology }\end{array}$ & \\
\hline
\end{tabular}


Appendix 2: Data extraction and quality of reporting

Data Incorporation:

Deterministic methodology

Probabilistic methodology

Sensitivity analysis

Were sensitivity analysis carried out $(\mathrm{Y} / \mathrm{N})$

Were $95 \% \mathrm{CI}$ for RRS used for sensitivity analyses

Which analyses

Was the discussion of sensitivity analyses

Please tick

\begin{tabular}{|l|l|l|l|}
\hline & \multicolumn{3}{|c|}{} \\
\hline & \multicolumn{3}{|c|}{} \\
\hline & Poor & Reasonable & Good \\
\hline
\end{tabular}

Internal validation

Was there evidence that the model had

undergone debugging

Was there evidence that the model had been

calibrated

How was the model calibrated? (describe)

Was the predictive validity of the model tested? $(\mathrm{Y} / \mathrm{N}) \ldots \ldots$.

How was the predictive validity of the model

checked? (Describe)

How was the validity quantified?

e.g. \% explained

Potential Limitations

\begin{tabular}{|l|l|l|l|l|}
\hline Potential Limitations & Not Reported & Reported & Discussed & $\begin{array}{l}\text { Method } \\
\text { refined }\end{array}$ \\
\hline Assumptions & & & & \\
\hline Confounding & & & & \\
\hline Lag times & & & & \\
\hline Competing causes & & & & \\
\hline
\end{tabular}

Involvement of policy makers, planners and decision makers in model:

\begin{tabular}{|l|l|}
\hline Who was involved? & \\
\hline How and at what stage were they involved? & \\
\hline Will policy makers, planners and decision & \\
makers have an opportunity to respond to & \\
the results of the study? & \\
\hline
\end{tabular}

Other comments on the study: 
Appendix 2: Data extraction and quality of reporting

\section{Overall summary}

\begin{tabular}{|l|l|}
\hline purpose and aim 4 & \\
\hline Transparency 3 & \\
\hline Data 1 & \\
\hline Data modelling 3 & \\
\hline Sensitivity analysis 2 & \\
\hline Internal validity 1 & \\
\hline Calibration 1 & \\
\hline Involvement of policymakers 1 & \\
\hline predictive validity 3 & \\
\hline Discussion of limitations 1 & \\
\hline Overall mark /20 & \\
\hline
\end{tabular}

